\title{
Apple Novelties Introduced in the Public Apple Tasting Held at Holovousy on January $4^{\text {th }}, 2018$
}

\author{
Jan Blažek*, František Paprštein and Jana Křelinová \\ Research and Breeding Institute of Pomology Holovousy Ltd., Czech Republic
}

Received: February 07, 2018; Published: February 19, 2018

*Corresponding author: Jan Blažek, Research and Breeding Institute of Pomology Holovousy Ltd., Holovousy 1, 50801 Horice, Czech Republic, Email: Jan.BLAZEK@vsuo.cz, blazek@vsuo.cz

\begin{abstract}
On January 4th in Holovousy a traditional apple tasting was held in which 121 largely experienced evaluators took part. The final sequence of each item in each variety was based upon the sum of point scorings of smell, character of skin, flesh consistence, flesh juiciness, fruit appearance and double scoring the value for taste in general. Based upon final results, 'Angold' was this time surprisingly placed. This cultivar was assessed as the best not only in taste in general, but also in flesh consistence and flesh juiciness. According to smell, it was assessed in second place; however in fruit appearance it occupied only the 19th position. 'Angold' in the general sequence was followed by two new novelties ('HL 2010' and 'HL 2350') which were publicly tasted for the first time. Next in order were placed the cultivars 'Meteor', the selection 'HL 1194' and 'Santana'.
\end{abstract}

Keywords: Apples; Cultivars; Consumer preference testing; Fruit quality; Fruit appearance; Cultivar assessing

\section{Introduction}

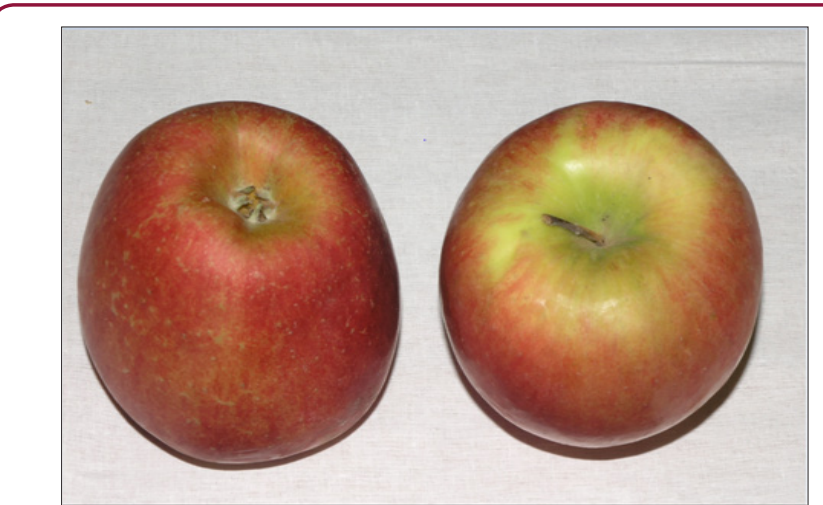

Figure 1: Angol.

Consumer preference testing of selected apple cultivars and advanced selections involving both specialists in the area and participants from the wide public are annually organized by the Research and Breeding Institute of Pomology Holovousy. The results of the consumer preference testing from previous years were usually published annually in journals [1-3]. Similar sensory evaluations of apple cultivars also took place in Germany [4]. Fruit traits desirable for the evaluation of apple cultivars include flavour, juiciness, sweetness, firmness, acidity, size, and colour [5,6]. As a standard, the cultivar 'Golden Delicious' has been used the most often at sensory apple consumer preference testing sessions [2].
The storing properties of 'Golden Delicious' apples were studied in Canada around 30 years ago [7]. There, fruits stored in standard control conditions at $0 \mathrm{C}$ for 5 to 6 months were in good condition after storage and were ready for consumption after ripening at $20 \mathrm{C}$ for 7 days (Figure 1\&2).

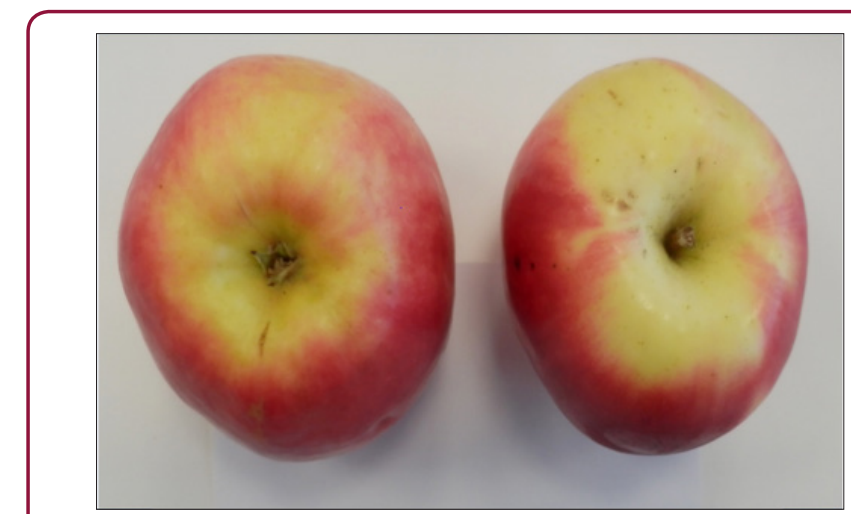

Figure 2: HL2010.

The organoleptic properties of new cultivars were frequently an integral part of their descriptions [8]. Similarly, consumer preference testing properties of fruits are typically used in the description of apple novelties (Funke and Blanke, 2011). Fruit quality and fruit colouration are important characteristics at present in the European market, and new apple cultivars can 
significantly contribute positively to the current trend [9]. Enhanced fruit quality is one of the main objectives across the range of apple breeding programs. Fruit quality is frequently associated with pest- and disease-resistance of particular cultivars [10]. The overall quality of apple cultivars can also be considered within trends in the common apple market. Thus, in the US where the most popular are the cultivars 'Red Delicious' and 'Gala' there are consumers willing to pay a high price for both cultivars, but the effect of sweetness is higher for 'Gala' apples [11]. The most important novelty in this market is 'Honeycrisp'; in the period from March 2009 to February 2015 the consumer price index for the cultivar increased by 3.14 cents per pound, of which 2.98 cents is explained by the increased number of total apple varieties and 0.16 cents by the decline in prices of competing apple varieties [12] (Figure 3\&4).

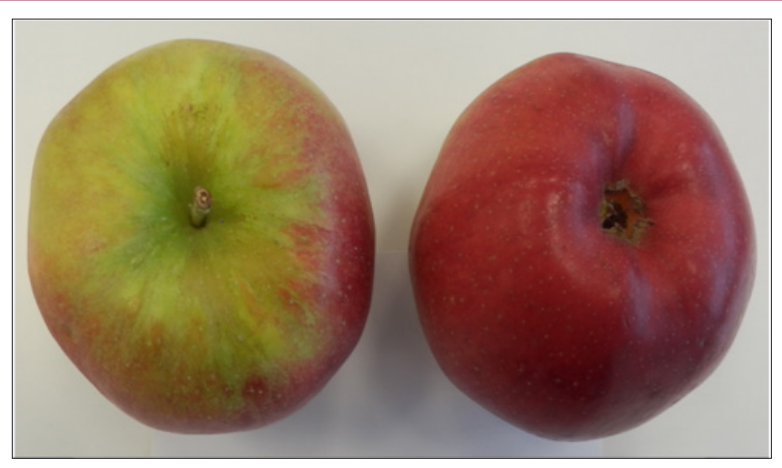

Figure 3: HL2350.

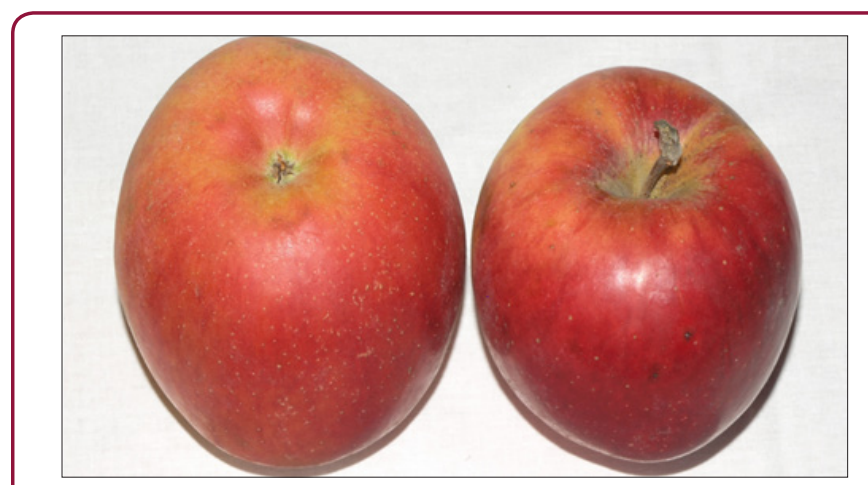

Figure 4: Meteor.

The cultivar 'Honeycrisp' originated in 1974, patented in 1988 and released in 1991. Its parental goneology is the following 'Keepsake' ('MN447' x 'Northern Spy') x unknown father. It has rapidly become a prized commercial commodity, as its sweetness, firmness, and tartness make it an ideal apple for eating raw (Howard et al., 2017, Nosowitz 2017). Individual cultivars are readily recognized in the market by consumers based on their appearance, flavor and texture. Consequently, variety denominations or trademarks are used to represent cultivars as brands to consumers [13]. Aside from fruit quality, also scab resistance of apple cultivars has accelerated around the world in recent years. A number of new varieties have been introduced to the marketplace. Some of these varieties are now available to growers and others will be introduced as club varieties. These new varieties have ever-improving quality and can be the canter-piece of organic apple production [14]. The main reason for the tasting session presented in this study was to compare several promising novelties with the best apple cultivars grown in the Czech Republic.

\section{Material and Methods}

In this public apple tasting session held on January $4^{\text {th }}$ in Holovousy, 121 largely experienced evaluators took part. There, in total 43 samples of chosen cultivars and breeding selections were anonymously in toss sequence evaluated. Among them, 23 were supplied by the department of Genetics and Breeding and 20 were from the apple cultivar collection of the Institute. During the evaluation of each item, fruits were sliced into small sections and distributed on plates to each of the testers. They tasted them and subsequently recorded their rating of the evaluated characteristics based upon a 1-9 rating scale (in which 9 designates the best or ideal performance) into their sheets in the following sequence: smell, skin thickness, consistency of the flesh, its juiciness, taste according to the relation of acidity to sweetness, and taste in general. The only one exception to this classification was the characterization of taste according to acidity, where the value 9 designated the sweetest fruits and the value 1 the most acidic ones.

The appearance of the fruits was evaluated after the consumer preference testing session based upon their exhibition, where each item was numerically identified by sequence in the consumer preference testing. This consecutive rating of fruit appearance was based on fruit size and shape, extent of overall colour and its attractiveness, presence and extent of skin russet (negative), and absence of other visual damage. The total point value was obtained by summing the scores for smell, skin thickness, flesh consistency, flesh juiciness, fruit appearance and doubling the value for fruit taste. The character of taste according to acidity is given only as a supplementary index of fruit quality and was not included in the total point value. At the end, all the evaluated cultivars and breeding selections were ranged downwards in sequence based upon the decreasing mean total point values in the final table of results, and in the single rows were further given their mean point values of all the evaluated characteristics and sequences that are presented in (Table 1).

Table 1: Overall results of fruit quality scoring.

\begin{tabular}{|c|c|c|c|c|c|c|c|c|c|c|c|c|c|c|c|c|}
\hline \multirow{2}{*}{ Cultivar } & \multicolumn{2}{|c|}{ Total score } & \multicolumn{2}{|c|}{ Smell } & \multicolumn{2}{|c|}{ Skin } & \multicolumn{2}{|c|}{$\begin{array}{c}\text { Flesh } \\
\text { consistence }\end{array}$} & \multicolumn{2}{|c|}{ Flesh juiciness } & \multicolumn{2}{|c|}{$\begin{array}{l}\text { Acidity to } \\
\text { sweetness }\end{array}$} & \multicolumn{2}{|c|}{ Total taste } & \multicolumn{2}{|c|}{$\begin{array}{c}\text { Fruit } \\
\text { appearance }\end{array}$} \\
\hline & points & seqen. & points & seqen. & points & seqen. & points & seqen. & points & seqen. & points & seqen. & points & seqen. & points & seqen. \\
\hline Angold & 46,88 & 1 & 6,88 & 2 & 5,61 & 17 & 6,56 & 1 & 6,81 & 1 & 6,34 & 6 & 7,07 & 1 & 6,88 & 19 \\
\hline HL 2010 & 45,15 & 2 & 6,89 & 1 & 4,85 & 32 & 6,54 & 2 & 6,28 & 9 & 5,96 & 15 & 6,92 & 2 & 6,75 & 21 \\
\hline
\end{tabular}




\begin{tabular}{|c|c|c|c|c|c|c|c|c|c|c|c|c|c|c|c|c|}
\hline HL 2350 & 44,55 & 3 & 5,98 & 11 & 6,43 & 4 & 6,13 & 17 & 6,20 & 12 & 5,13 & 33 & 6,35 & 12 & 7,13 & 9 \\
\hline Meteor & 44,52 & 4 & 5,79 & 20 & 6,11 & 5 & 6,16 & 14 & 6,77 & 2 & 5,21 & 32 & 6,29 & 16 & 7,13 & 10 \\
\hline HL 1194 & 43,82 & 5 & 6,03 & 9 & 5,63 & 16 & 6,09 & 19 & 6,35 & 6 & 6,06 & 14 & 6,43 & 9 & 6,88 & 20 \\
\hline Santana & 43,79 & 6 & 5,99 & 10 & 4,28 & 41 & 6,37 & 4 & 6,32 & 7 & 6,38 & 5 & 6,67 & 5 & 7,50 & 1 \\
\hline HL 53 & 43,57 & 7 & 6,52 & 4 & 5,42 & 20 & 6.05 & 21 & 5,62 & 27 & 6,19 & 10 & 6,42 & 10 & 7,13 & 8 \\
\hline Rucla & 43,48 & 8 & 5,67 & 25 & 5,30 & 23 & 6,37 & 3 & 6,13 & 13 & 5.54 & 24 & 6,45 & 8 & 7,13 & 7 \\
\hline HL 72 & 43,48 & 9 & 6,12 & 6 & 5,67 & 12 & 6,10 & 18 & 5,69 & 24 & 6,20 & 9 & 6,33 & 13 & 7,25 & 5 \\
\hline HL 1355 & 43,45 & 10 & 5.96 & 12 & 5,23 & 26 & 6,32 & 6 & 6,46 & 3 & 5,54 & 25 & 6.73 & 3 & 6,00 & 31 \\
\hline Rubinstep & 43,44 & 11 & 5,90 & 16 & 5,32 & 22 & 6,18 & 11 & 5,66 & 25 & 5,77 & 17 & 6,56 & 7 & 7,25 & 4 \\
\hline Jonaprince & 43,00 & 13 & 5,96 & 13 & 4,31 & 40 & 6,16 & 15 & 5,99 & 16 & 6,29 & 7 & 6,60 & 6 & 7,38 & 2 \\
\hline Melrose & 43,00 & 12 & 6,04 & 8 & 5,54 & 19 & 6,21 & 8 & 6,29 & 8 & 4,97 & 36 & 6,21 & 18 & 6,50 & 26 \\
\hline Reluga & 42,89 & 14 & 5,60 & 30 & 6,01 & 6 & 5,88 & 26 & 5,99 & 17 & 4,94 & 37 & 6,14 & 22 & 7,13 & 11 \\
\hline Gala Schniga & 42,83 & 15 & 6,07 & 7 & 5,19 & 27 & 6,18 & 12 & 5,57 & 28 & 6,63 & 3 & 6,29 & 15 & 7,25 & 6 \\
\hline Lady Silvia & 42,68 & 16 & 5,66 & 27 & 4,89 & 31 & 6,35 & 5 & 5.87 & 18 & 5,60 & 23 & 6,71 & 4 & 6,50 & 24 \\
\hline HL 207 & 42,44 & 17 & 5,92 & 15 & 4,74 & 34 & 6,08 & 20 & 5,86 & 19 & 5,96 & 16 & 6,42 & 11 & 7,00 & 13 \\
\hline Rubin & 42,42 & 18 & 6,54 & 3 & 4,27 & 42 & 6,15 & 16 & 5,77 & 21 & 5,66 & 20 & 6,16 & 19 & 7,38 & 3 \\
\hline HL 1199 & 42,29 & 19 & 5,58 & 31 & 5,08 & 28 & 6,20 & 9 & 6,13 & 14 & 5,04 & 34 & 6,15 & 20 & 7,00 & 14 \\
\hline HL 617-11 & 41,72 & 20 & 5,67 & 26 & 5,65 & 14 & 5,89 & 25 & 5,63 & 26 & 5,22 & 31 & 5,88 & 29 & 7,13 & 12 \\
\hline HL 1304 & 41,65 & 21 & 5,39 & 38 & 6,70 & 1 & 5,43 & 35 & 5,29 & 35 & 6,25 & 8 & 5,92 & 26 & 7,00 & 17 \\
\hline HL 298 & 41,62 & 22 & 6.21 & 5 & 5,65 & 13 & 5,80 & 29 & 5,54 & 29 & 7,38 & 1 & 6,14 & 21 & 6,13 & 29 \\
\hline $\begin{array}{c}\text { Jonagored } \\
\text { Supra }\end{array}$ & 41,60 & 23 & 5,76 & 22 & 4,38 & 39 & 6,21 & 7 & 6,23 & 10 & 5,63 & 21 & 6,26 & 17 & 6,50 & 25 \\
\hline $\begin{array}{c}\text { King } \\
\text { Jonagold }\end{array}$ & 41,41 & 24 & 5,68 & 24 & 4,51 & 38 & 6,19 & 10 & 6,42 & 4 & 5,45 & 27 & 6,30 & 14 & 6,00 & 32 \\
\hline HL 366 & 41,28 & 25 & 5,56 & 33 & 4,22 & 43 & 6.18 & 13 & 6,22 & 11 & 4,78 & 38 & 6,04 & 24 & 7,00 & 15 \\
\hline Jomured & 41,19 & 26 & 5,65 & 28 & 4,53 & 37 & 5,93 & 24 & 6,12 & 15 & 5,51 & 26 & 5,98 & 25 & 7,00 & 16 \\
\hline Slendera & 40,97 & 27 & 5,71 & 23 & 5,90 & 9 & 5,72 & 33 & 5,47 & 31 & 5,61 & 22 & 5,71 & 31 & 6,75 & 22 \\
\hline Artiga & 40,80 & 28 & 5,43 & 37 & 5,84 & 10 & 5,77 & 31 & 6,38 & 5 & 4,12 & 43 & 5,63 & 33 & 6,13 & 30 \\
\hline Benet & 40,47 & 29 & 5.56 & 34 & 5,04 & 29 & 6,00 & 22 & 5,71 & 23 & 5,35 & 30 & 5,89 & 27 & 6,38 & 27 \\
\hline HL 245 & 40,27 & 30 & 5,57 & 32 & 5,63 & 15 & 5,88 & 27 & 5,86 & 20 & 4.78 & 39 & 5,79 & 30 & 5,75 & 39 \\
\hline Ariane & 40,13 & 31 & 5,93 & 14 & 5,96 & 8 & 5,78 & 30 & 5,50 & 30 & 5,02 & 35 & 5,54 & 34 & 5,88 & 36 \\
\hline Rubens & 40,04 & 32 & 5,61 & 29 & 5,27 & 25 & 5,95 & 23 & 5.72 & 22 & 6,08 & 13 & 5,88 & 28 & 5,75 & 38 \\
\hline $\begin{array}{c}\text { Golden Del. } \\
\text { Reinders }\end{array}$ & 39,44 & 33 & 5,79 & 21 & 4,61 & 36 & 5,73 & 32 & 5,31 & 34 & 6,43 & 4 & 5.69 & 32 & 6,63 & 23 \\
\hline Annurca & 39,09 & 34 & 5.79 & 19 & 4,67 & 35 & 5,88 & 28 & 5.44 & 32 & 6,10 & 11 & 6,09 & 23 & 5,13 & 41 \\
\hline Pinova & 39,07 & 35 & 5,84 & 18 & 5,56 & 18 & 5,62 & 34 & 5,20 & 38 & 5,73 & 18 & 5,43 & 35 & 6,00 & 33 \\
\hline Bonza & 38,90 & 36 & 5,46 & 36 & 5.98 & 7 & 5,34 & 38 & 5,21 & 37 & 5,45 & 28 & 5,27 & 37 & 6,38 & 28 \\
\hline Fragrance & 38,48 & 37 & 5,47 & 35 & 5,29 & 24 & 5,39 & 36 & 4,79 & 41 & 6,74 & 2 & 5,27 & 36 & 7,00 & 18 \\
\hline Starkrimson & 38,42 & 38 & 5,89 & 17 & 6,52 & 3 & 5,29 & 40 & 5,12 & 40 & 6,09 & 12 & 4,80 & 40 & 6,00 & 35 \\
\hline Fuji Bc 2 & 37,19 & 39 & 5,13 & 40 & 6,54 & 2 & 5,21 & 41 & 5,38 & 33 & 5,72 & 19 & 5,16 & 38 & 4,63 & 42 \\
\hline Idared & 36,12 & 40 & 4,99 & 42 & 4.93 & 30 & 5,29 & 39 & 5,19 & 39 & 4,31 & 42 & 4,86 & 39 & 6,00 & 34 \\
\hline Falstaff & 35,95 & 41 & 5,21 & 39 & 4,82 & 33 & 5,35 & 37 & 5,29 & 36 & 4,32 & 41 & 4,71 & 41 & 5.88 & 37 \\
\hline Florina & 35,66 & 42 & 5,04 & 41 & 5,78 & 11 & 5,10 & 42 & 4,73 & 42 & 5,36 & 29 & 4,70 & 42 & 5,63 & 40 \\
\hline Podzvičinské & 32,69 & 43 & 4,89 & 43 & 5,41 & 21 & 4,82 & 43 & 4,40 & 43 & 4,65 & 40 & 4,27 & 43 & 4,63 & 43 \\
\hline LSD, $\mathrm{P}>0.05$ & 1.36 & & 0.39 & & 0.24 & & 0.37 & & 0.28 & & 0.35 & & 0.29 & & 0.32 & \\
\hline
\end{tabular}




\section{Results}

Within this tasting session, 'Angold' was surprisingly placed at the top of the entire sequence among the total set of all the evaluated cultivars and selections. It was assessed as the best in taste general, but also in flesh juiciness and consistency. According to the smell, it was assessed as the second, however in fruit appearance it was placed in the $19^{\text {th }}$ position. 'Angold' was bred at Holovousy based upon a crossing of selection 'HL 28/39' ('Antonovka o.p.') and ' Golden Delicious : As a new cultivar, it was registered in the year 1995. Fruits of 'Angold' are ranged as large to extralarge (182$243 \mathrm{~g}$ ). Their colour is a very pale cream to green in the background, mostly covered over by dark red distributed by blush and striping. They are storable in a cold storage up to April. This cultivar is highly tolerant both to scab and mildew. Next in position in the total fruit quality sequence was the novelty 'HL 2010', which originated by crossing the selection 'HL 665' ('Spartan' x 'Antonovka o.p.') and the cultivar 'Cripps Pink'. It was ranged as the best in fruit smell and as the second in total taste and flesh consistency.

Its fruits are harvested during the first days of October and are storable until the end of April. Fruits have a higher content of antidegradants. The tree vigour is on the medial level, trees are precocious in fruiting and their cropping is regular and the above average level. They are resistant to scab and less susceptible to mildew. In the third position of the total sequence was the novelty 'HL 2350', which originated at Holovousy by crossing the cultivars 'Golida' and 'Benet'. It had fine skin, where it was placed in the 4th position, and its fruits were considered quite attractive. Its fruits are harvested during the first days of October and are storable until the end of May. The tree vigour is slightly above the medial level, tree productivity is sufficient and quite regular. Trees are tolerant to scab and medium susceptible to mildew. The next cultivar in the total quality sequence was 'Meteor', which originated in Holovousy by crossing the cultivars 'Megumi' and 'Melrose'. In its fruit characteristics there are optimally combined properties of both its parents. It was rated best in flesh juiciness and fruit skin.

The fruits are ready for harvest in the middle of October and are storable until the end of June. The tree vigour of this cultivar is medium vigorous and its start of fruiting is medium late. Trees are susceptible to scab and moderately susceptible to mildew. Following in the sequence was the novelty 'HL 1194', which originated by crossing the cultivars 'Golida' and 'Topaz'. It was quite highly evaluated in fruit juiciness, in total taste and fruit smell. Fruits are ready for harvest in the first days of October and are storable until the end of April. Cropping of trees is rather high and regular. This cultivar is resistant to scab and less susceptible to mildew. Next in position was 'Santana', which was the best among the cultivars that originated abroad. It was outstanding in fruit appearance, where it was rated in the first position. It was also very good in total taste ( $5^{\text {th }}$ position $)$ and its flesh was sweet and juicy. It was bred in Holland by crossing 'Elstar' and 'Priscilla' in the 70s of the last century but it is grown only since 2006.

It is tolerant to diseases, mainly to scab. In the $7^{\text {th }}$ position was the selection 'HL 53', which originated by crossing the cultivars 'Melrose' and 'Rubinola'. It had interesting fruit smell and fruit appearance. The next one in the total rating was 'Rucla', which originated in Holovousy by crossing the cultivars 'Clivia' and 'Rubín'. It was quite well-rated in flesh consistency and fruit appearance. It was followed by the selections 'HL 72' ('Melrose' $\mathrm{x}$ 'Rubinola') and 'HL 1355' ('Golida' $x$ 'Benet'); behind those were the cultivars 'Rubinstep' and 'Jonaprince'. Both the last ones were well evaluated in fruit appearance. The popular Czech cultivar 'Rubín' was this time placed only in the 18th position of the total sequence, but in the evaluation of fruit smell and fruit appearance it was the third best. As the absolute sweetest, the title was attained by the selection 'HL 298' ('Megumi' x 'Rubín'); but in the total sequence the cultivar was ranged further down in the $28^{\text {th }}$ position.

\section{Discussion}

Ratings of the standard cultivars 'Jonagold', 'Golden Delicious', 'Starkrimson Delicious', and 'Idared' were generally lower than in our previous tastings $[2,15]$. Their samples may have been slightly overripe due to extremely high temperatures during the apple harvest season in Holovousy last year. Particularly the tasting assessments of 'Golden Delicious' fruits considerably depend upon their stage of overall maturity. 'Jonagold' was frequently published as a taste-test winner. In the study of consumer preferences in the US, 'Jonagold' was very well evaluated in appearance, aroma, texture, flavor, and overall likability expression [16]. In Germany, however, it was better scored if assessed before December [4]. A particular problem in the innovation of the present apple assortment is that new cultivars possessing resistance to pest or diseases are still mainly inferior in fruit quality to standard ones [10]. It seems that a few novelties evaluated here could solve this problem in the future. The great change for commercial distribution should have those resistant to diseases [17-19].

\section{Acknowledgement}

Supported by the Ministry of the Education, Youth and Sports of the Czech Republic, Project No. MSM 2527112101, infrastructure of the Project No. CZ. 1.05/2.1.00/03.0116.

\section{References}

1. Paprštein F, Blažek J (1998) Výsledkydegustacejablek 1998 (Results from apple sensory evaluation held in 1998). Marketing ovoce 5(4): 8-13.

2. Blažek J, Paprštein F (2012) The results of the organoleptic evaluation of stagnant apples held in Holovousy (results from the sensory evaluation of storable apples held at Holovousy). Horticulture 11(8): 14-15.

3. NesrstaD ( $\left.\begin{array}{llll}2 & 0 & 1 & 3\end{array}\right)$ Organoleptickéhodnoceníjablek, jakjejohodnotilaodbornáveřejnost (Organoleptic evaluation of apples, how is it appreciated by expert public). Vinař-Sadař 1: 60-61.

4. Stehr R (2011) German consumer ratings include new apple varieties. Arboriculture 6: 324-327.

5. Kellerhals M, Ganter SC (2004) New apple varieties on the test bench. Switzerland Z. Fruit and Viticulture 12: 8-11.

6. Eigemann NC, Kellerhals M (2007) Which apples do consumers want? Agricultural Research 14: 6-9.

7. Lau QL, Yastremski R (1991) Retention of quality of 'Golden Delicious' apples by controlled- and modified-atmosphere storage. HORTSCIENCE 26(5): 564-566. 
8. Milosevic CN, Milosevic T, Glasic I (2009) Productive and organoleptic traits of recent apple cultivars. Acta Horticulturae 825: 565-570.

9. Blanke M, Dixon GR (2009) The structure of coloured hail nets affects light transmission, light spectrum, phytochrome, and photosynthesis and apple fruit colouration. Acta Horticulturae 817: 177-184.

10. Stoecki S, Mody K, Dorn S, Kellerhals M (2011) Association between herbivore resistance and fruit quality in apple. Hortscience 46(1): 12-15

11. McCluskey JJ, Horn BP, Durham CA, Mittelhammer RC, Hu Y (2013) Valuation of internal quality characteristics across apple cultivars. Agribusiness 29 (2): 228-241.

12. Wang Y, Çakır M (2018) The welfare impacts of new demand-enhancing agricultural products: The case of Honeycrisp apples. Paper presented at the 2018 Annual Meeting of the Allied Social Science Associations, Philadelphia, PA, USA.

13. Luby JJ, Bedford DS (2015) Cultivars as consumer brands: Trends in protecting and commercializing apple cultivars via Intellectual property rights. Crop Science 55(6): 2504-2510.

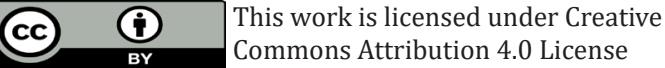

Submission Link: http://biomedres.us/submit-manuscript.php
14. Brown S, Maloney K (2008) Scab-resistant cultivars (Varieties). New York Fruit Quartely 16(4): 3-6.

15. Blažek J, Paprštein F (2014) Development of fruit quality within top apple cultivars based on the preference testing in last 34 years. Hort. Sci. (Prague) 41(1): 10-18.

16. Kelley K, Hyde J, Travis J, Crasweller R (2010) Assessing Consumer preferences of scab-resistant apples: A sensory evaluation HortTechnology 20(5): 885-891.

17. Blažek J, Paprštein F (1994) Breeding apples for scab tolerance at Holovousy. Progress in Temperate Fruit Breeding, Kluwer Academic Publishers, p. 21-25.

18. Blažek J (2013) Comparative study of apple cultivars bred in Holovousy, Czech Republic. Journal of Plant Studies 2(2): 113-121.

19. Mc Cluskey JJ, Horn BP, Durham CA, Mittelhammer RC, Hu Y (2013) Valuation of internal quality characteristics across apple cultivars. Agribusiness 29(2): 228-241.

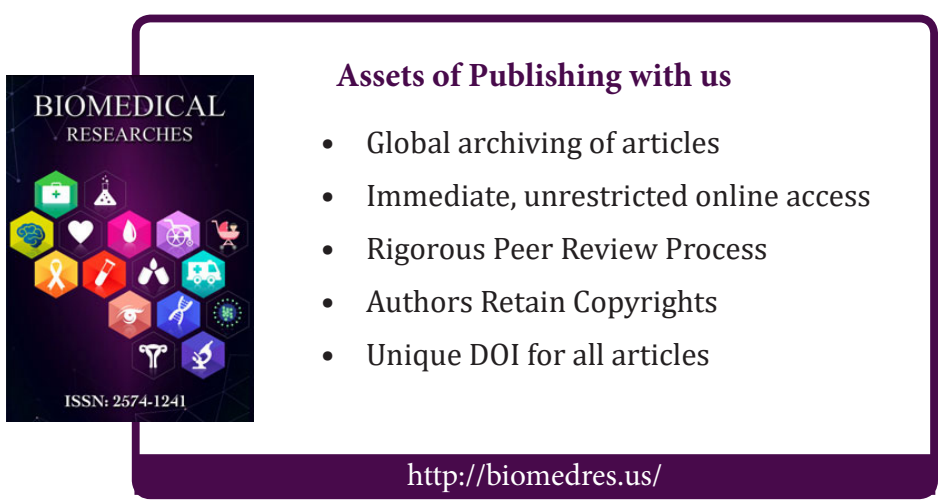

